\title{
Investigation of Effect of Ripening and Processing on Prebiotic Potential of Banana
}

\author{
Jayashri Gajananrao Mahore*, Satish Vasudeo Shirolkar \\ Department of Pharmaceutics, Dr. D. Y. Patil Institute of Pharmaceutical Sciences and Research, Pimpri, Pune, Maharashtra, INDIA.
}

\begin{abstract}
Objective: Daily consumption of raw banana improves human health because of its resistant starch. Breakdown of starch during ripening and processing, makes it unavailable for fermentation by gut microbiota. The objective of this study was to evaluate the effect of ripening and processing on prebiotic potential of banana. Methods: Fermentation ability has been assessed in vitro and in vivo. In vitro prebiotic evaluation of banana was carried out for raw, ripe and processed banana as a sole carbon source in modified medium. In vivo evaluation was carried out after 4 weeks of administration of raw and ripe banana pulp flour to male Wistar rats. Results and Discussion: In vitro prebiotic evaluation of banana resulted increase in Lactobacillus acidophilus populations, $\mathrm{pH}$ reduction, increase in total titratable acidity than control. In a 4-week animal trial, daily administration of raw banana pulp flour increased CFU/gm of Lactobacillus species in caecum content and lowered the $\mathrm{pH}$ of the caecum significantly. Acidic $\mathrm{pH}$
\end{abstract}

of gut created by fermentation of prebiotic provides unfavorable condition for the growth of pathogens. Bacteriocin produced by Lactobacilli inhibited the growth of pathogens. Protection of large intestine from pathogens improves health of large intestine. Physicochemical changes during ripening and processing significantly reduced the prebiotic potential of banana.

Key words: Banana, Lactobacillus acidophilus, Prebiotic.

Correspondence

Ms. Jayashri Gajananrao Mahore, Department of Pharmaceutics, Dr. D. Y. Patil Institute of Pharmaceutical Sciences and Research, Pimpri, Pune, Maharashtra, INDIA.

Email: jayashri_mahore@rediffmail.com

DOI: 10.5530/jyp.2018.10.90

\section{INTRODUCTION}

Banana (Musa acuminata) is the popular nutritious food ingredient of South Indian dishes. Banana is mostly consumed either in raw, ripe and processed form in South India. Keralites (people from the Kerala) give raw banana powder to their children since long time. Starch and fibre imparts typical starchy taste to raw banana and decrease its palatability. ${ }^{1}$ every medium sized banana is rich source of carbohydrate with low fat content. Banana is also a good source of vitamin $\mathrm{B}_{6}$, potassium and vitamin C. Raw banana is rich in resistance starch (RS), which is not absorbed in the small intestine of healthy individual. ${ }^{2} \mathrm{RS}$ has attracted interest due to its health effect on the colon. ${ }^{3}$ Fermentation of resistant starch in large intestine produces short chain fatty acids (SCFAs), carbon dioxide, methane and hydrogen. SCFAs are volatile fatty acids existing in straight- and branched-chain conformations. Common SCFAs include formic, acetic, propionic, butyric, isobutyric, valeric, isovaleric, and caproic acids. Acetic, propionic and butyric acids were studied extensively for beneficial effect on human health. It reduces $\mathrm{pH}$ of the colon, prevents the formation of carcinogenic amines, improves fecal excretion, and mainly butyrate protects the bowels from colon cancer. ${ }^{4}$

The enzymes initiate chemical reactions as well as accelerate the reaction during ripening. ${ }^{5,6}$ Physical and chemical changes occur during ripening impart soft texture and sweet taste to banana and improve palatability of ripe banana. High percentage of sugar imparts sweet taste to ripe banana. ${ }^{7}$ Banana chips, processed form of banana is mostly accepted throughout the world. Frying is routinely used method to prepared banana chips. Frying affects the prebiotic potential of raw banana. Among various banana products on market, fried chips and candy hold major share of market. ${ }^{2}$ Most of the investigators explored the effect of roasting on prebiotic potential of other materials. very few data is available for effect of frying on prebiotic potential.

The effect of ripening and frying on fermentation of banana is less studied. So, the aim of present study was to investigate effect of raw, ripe and processed banana on the growth of Lactobacilli and to investigate in vivo prebiotic efficacy of raw and ripe banana pulp.

\section{MATERIALS AND METHODS}

\section{Preparation of banana pulp flour (BPF)}

Raw (banana with full green peel, stage 1 of ripening) and ripe (banana with full yellow, stage 6 of ripening) bananas were obtained from local market, Pune. Peeled fruits were cut into slices. Slices were then dipped in $0.5 \%(\mathrm{w} / \mathrm{v})$ citric acid solution for $10 \mathrm{~min}$, to avoid browning, drained and dried in oven at $60^{\circ} \mathrm{C}$ for $18 \mathrm{hr}$. The dried samples were ground in a household grinder. The powder was to pass through 60 mesh screens to obtain banana flour. ${ }^{8}$ Raw and ripe banana was sliced using slicer and then deep fried in ground nut oil. Fried chips were kept on tissue paper to absorb excess oil. Fried chips were converted into powder described above.

\section{Probiotic culture maintenance}

The starter culture of Lactobacillus acidophilus was procured from National Collection of Industrial Microorganism (NCIM-5426), Pune (MS, India). The culture was maintained on deMan Rogosa Sharpe (MRS) agar (Himedia, India) at $37^{\circ} \mathrm{C}$ for $24 \mathrm{~h}$. Sub-culturing was done in MRS media every 15 days. 


\section{Growth of L. acidophilus on BPF}

MRS broth is extensively studied selective medium for growth of Lactobacillus. Modified MRS broth was prepared as per the method described by Mandalari et al. (2007). ${ }^{9}$ using BPF as sole carbon source medium. BPF was added to the broth at a final concentration of $5 \%$ The experimental media was sterilized at $121^{\circ} \mathrm{C}$ for $15 \mathrm{~min}$ before inoculation. Colonies isolated from MRS agar plates were pre-cultured twice in MRS liquid broth at $37^{\circ} \mathrm{C}$, first for $24 \mathrm{~h}$ and then for $18 \mathrm{~h}$, to ensure that all the cells were harvested from the early stationary phase. The bacterial suspensions $2 \%(\mathrm{v} / \mathrm{v})$ was then used to inoculate the BPF medium. In all cases, the initial microbial concentration was approximately at $10^{7} \mathrm{CFU} / \mathrm{mL}$. Modified media was incubated in micro-aerophillic conditions for $48 \mathrm{~h}$. Samples were taken periodically to determine optical density, \% titratable acidity, $\mathrm{pH}$ and antimicrobial activity against E. coli.

\section{Monitoring of growth}

Growth of L. acidophilus was monitored by measuring optical density using UV-Visible spectrophotometer (Shimadzu Analytical Pvt. Ltd, Japan) at $600 \mathrm{~nm}$. Measured values of optical density were plotted on growth curves. The maximum specific speed for the growth was calculated during the exponential growth phase through the following equation (Kask et al. 2003): ${ }^{10}$

$\ln$ (optical density at the end of the exponential growth phase)-

$\mu_{\max }=\frac{\ln \text { (optical density at the beginning of the exponential growth phase) }}{\text { Time interval between observations }}$

The doubling time was determined through equation

$$
\mathrm{t}_{\mathrm{d}}=\ln 2 / \mu_{\max }
$$

Where, $\mu_{\max }-$ maximum specific growth rate, $\mathrm{t}_{\mathrm{d}}$ - doubling time

\section{Changes in $\mathrm{pH}$ of modified media containing banana pulp flour}

The $\mathrm{pH}$ was measured by an electronic digital type $\mathrm{pH}$ meter (EquipTronic, Mumbai, India). pH 4.0 and pH 7.0 buffer solutions were used to standardize the $\mathrm{pH}$ meter. Measured $\mathrm{pH}$ values were plotted on graphs. From graphs the rates of decrease of $\mathrm{pH}$ values were calculated.

\section{Titratable acidity}

$0.01 \mathrm{M} \mathrm{NaOH}$ with phenolphthalein as an indicator was used to measure the titratable acidity (as \% lactic acid). The \% titratable acidity was calculated by using formula: ${ }^{11}$

$$
\% \text { Titratable Acidity }=\frac{9 \times \text { titer value } \times \text { normality of } \mathrm{NaOH} \times \text { Dilution }}{\text { Weight of the sample taken }} \times 100
$$

\section{Antimicrobial activity against $E$. coli}

Cell-free supernatant was collected by centrifugation at 4,000 rpm for 15 min (C-24, Cooling centrifuge, Remi Instrument LTD, India). Antimicrobial assay was performed by agar well diffusion method. MacConkey agar was used to grow E. coli. Sterilized agar was allowed to solidify. Over night culture of $E$. coli was spread on solidified agar and $100 \mu \mathrm{L}$ of cell free supernatant was added in $6 \mathrm{~mm}$ wells. Plates were kept at $4^{\circ} \mathrm{C}$ for 4 $\mathrm{h}$ to facilitate diffusion. Then plates were incubated aerobically at $37^{\circ} \mathrm{C}$ for $24 \mathrm{~h}$. Zone of inhibition was recorded in duplicate.

\section{In vivo prebiotic potential of raw and ripe BPF}

Amongst raw, ripe and processed BPF, raw and ripe BPF showed comparatively good in vitro prebiotic efficacy to that of fried BPF. Hence only two samples were assessed in-vivo.

In a 4 weeks animal experiment, the male Wistar rats had free access to diet and water and were housed in ventilated room with a $12 \mathrm{~h}: 12 \mathrm{~h}$ light/ dark photoperiod at $23 \pm 2^{\circ} \mathrm{C}$. All procedures had approval of the Institute Animal Ethical Committee. After a week of acclimatization to experimental conditions, the rats were randomly divided into three groups $(n=6)$. Control (group-I) received distilled water; Group-II and Group III received raw and ripe BPF $(2 \mathrm{~g} /$ day $/ \mathrm{kg}$ of rat) suspended in distilled water. After 1 week of treatment stool samples were collected for every week and immediately stored at $4^{\circ} \mathrm{C}$. Freshly voided fecal material was collected to study faecal moisture, $\mathrm{pH}$ and bacterial concentrations. ${ }^{12}$ The water content of the luminal stools was calculated by weight difference between fresh and dried (kept during $24 \mathrm{~h}$ at $65^{\circ} \mathrm{C}$ ) samples. For $\mathrm{pH}$ measurement, faecal content was suspended in water, homogenized by vortexing and $\mathrm{pH}$ values was measured using a $\mathrm{pH}$-meter. At the end of $4^{\text {th }}$ week animals were scarified, transferred to laminar flow cabinet and caecum content was removed anaerobically. $\mathrm{pH}$ and bacterial count of caecum content was determined. Ten-fold serial dilutions were made in the medium and aliquots of $0.1 \mathrm{ml}$ of the appropriate dilution was spread onto the following agar media to determine bacterial count; MRS agar for lactobacilli and Rogosa agar (Himedia, India) supplemented with $0.5 \mathrm{~g} / \mathrm{L} \mathrm{L}$-cysteine hydrochloride for Bifidobacterium and culture plates were incubated microaerophically for Lactobacilli and anaerobically for Bifidibacteria at $37^{\circ} \mathrm{C}$ for $24-48$ h. ${ }^{13}$

\section{Microbiological analysis of caecum content}

For the isolation and counting of probiotic bacteria each one of the caecum samples were aseptically diluted by $0.1 \%(\mathrm{w} / \mathrm{v})$ sterile peptone water. Aliquots of these suspensions were transferred to test tubes containing $9 \mathrm{~mL}$ with the same peptone water, so as to obtain serial decimal dilutions $\left(10^{-1}\right.$ to $\left.10^{-6}\right)$.

Later, an aliquot of each diluted sample was transferred to plate dishes containing specific agar as described by Vinderola and Reinheimer et al. (1999). ${ }^{14}$ the counting was performed by a Colony Counter apparatus.

\section{Statistical analysis}

All the experiments were conducted at least twice and triplicate samples were used for each test. Data was collected and analyzed by using one way analysis of variance and Bonferroni's test. All statistical analysis was performed using Graph Pad InStat.

\section{RESULTS}

\section{Growth of L. acidophilus in presence of BPF}

Lag phase of L. acidophilus growth curve was decreased, and log phase was increased significantly after addition of raw BPF, as sole carbon source to modified MRS medium (Figure 1). Then, bacterial growth curve reached to stationary phase after $32 \mathrm{~h}$ and turned to be relatively constant for 48 h. High optical density of L. acidophilus was observed in presence of raw BPF (Figure 2).

\section{Growth kinetics}

The maximum specific growth rates $\left(\mu_{\max }\right)$ and the doubling time $\left(t_{d}\right)$ of the media containing different carbon source after $48 \mathrm{~h}$ of anaerobic fermentation are shown in Table 1.

L. acidophilus showed the fastest growth $\left(\mu_{\max }, 0.173 \mathrm{~h}^{-1}\right)$ on raw BPF compared to ripe $\left(\mu_{\max }, 0.028 \mathrm{~h}^{-1}\right)$ and processed one. Doubling time of $L$. acidophilus was very less in presence of raw BPF $\left(t_{d}, 4.006 \mathrm{~h}\right)$ 


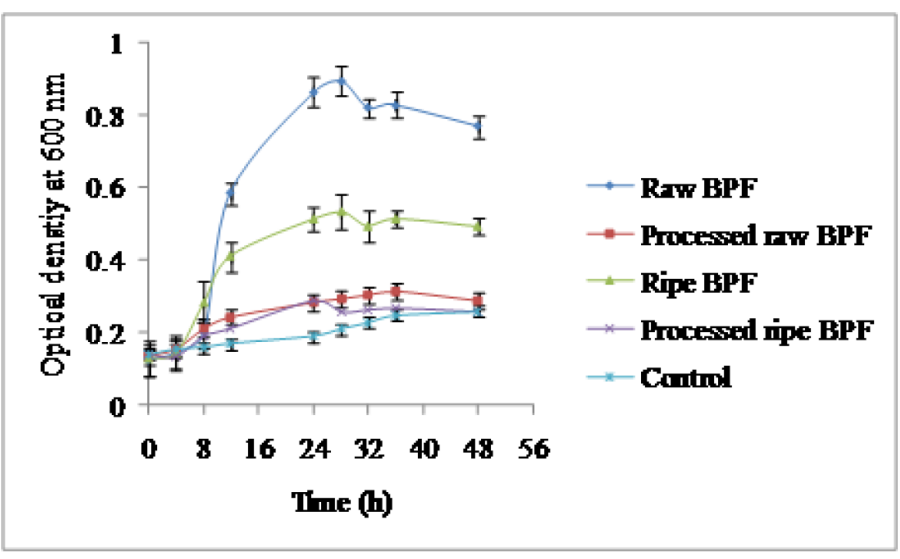

Figure 1: Growth of L. acidophilus in reconstituted MRS broth either with raw, ripe and processed BPF.

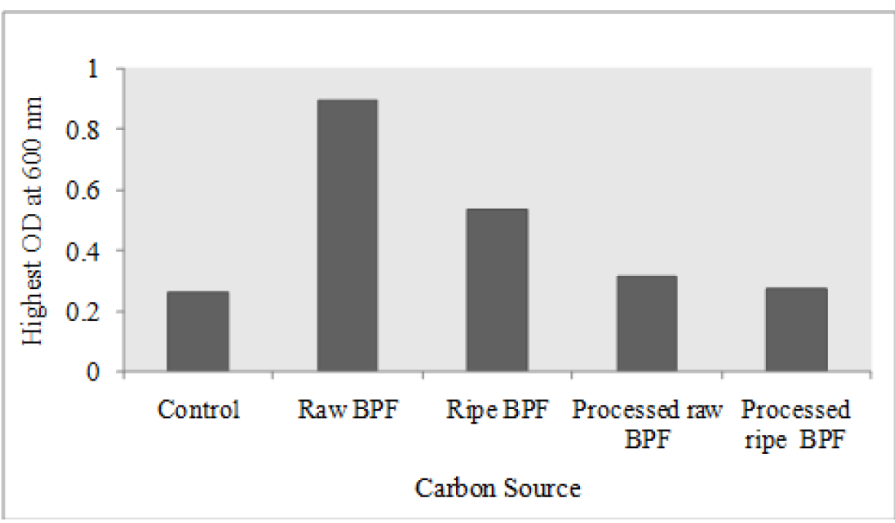

Figure 2: Maximum OD shown by L. acidophilus in presence of raw, ripe and processed BPF

Table 1: Growth kinetcs of $L$. acidphillus in presence of raw, ripe and processed BPF.

\begin{tabular}{ccccc}
\hline Sample & Raw BPF & $\begin{array}{c}\text { Processed } \\
\text { Raw BPF }\end{array}$ & Ripe BPF & $\begin{array}{c}\text { Processed } \\
\text { ripe BPF }\end{array}$ \\
\hline$\mu_{\max }\left(\mathrm{h}^{-1}\right)$ & 0.173 & 0.028 & 0.048 & 0.030 \\
Doubling Time $\left(\mathrm{t}_{\mathrm{d}}\right) \mathrm{h}$ & 4.006 & 24.75526 & 14.44057 & 23.10491 \\
\hline
\end{tabular}

Table 2: The titratable acidity of the medium supplemented with raw, ripe and processed banana inoculated with L. acidophilus.

\begin{tabular}{|c|c|c|c|c|c|}
\hline \multirow{2}{*}{$\begin{array}{c}\text { Incubation } \\
\text { time }\end{array}$} & \multicolumn{5}{|c|}{ Titratable acidity } \\
\hline & Control & Raw BPF & Ripe BPF & $\begin{array}{c}\text { Processed } \\
\text { raw BPF }\end{array}$ & $\begin{array}{c}\text { Processed } \\
\text { ripe BPF }\end{array}$ \\
\hline $24 \mathrm{~h}$ & $0.07 \pm 0.03$ & $1.71 \pm 0.07$ & $0.76 \pm 0.04$ & $0.35 \pm 0.06$ & $0.50 \pm 0.04$ \\
\hline $48 \mathrm{~h}$ & $0.09 \pm 0.04$ & $2.16 \pm 0.04$ & $1.15 \pm 0.09$ & $0.57 \pm 0.08$ & $0.79 \pm 0.05$ \\
\hline
\end{tabular}

Values presented as means $\pm \mathrm{SD}$.

which proves the ability of raw BPF content to support the growth of L. acidophilus.

\section{Changes in $\mathrm{pH}$ of fermentation media in presence of raw, ripe and processed BPF}

Addition of BPF reduces $\mathrm{pH}$ of modified MRS medium. Significant reduction in $\mathrm{pH}$ from $6.9(\mathrm{t}=0)$ to $5-5.5(\mathrm{t}=48 \mathrm{~h})$ showed by raw $\mathrm{BPF}$
(Figure 3). Rate of decrease in $\mathrm{pH}$ was highest in presence of raw BPF. Reduction in $\mathrm{pH}$ showed strong relationship to production of lactic acid which is main metabolic product produced by the Lactobacilli. Acidic $\mathrm{pH}$ generates unfavorable environment for the growth of pathogens.

\section{Titratable acidity}

Increase in percent titratable acidity (Table 2) was observed with raw BPF; $2.16 \pm 0.04$ to that of ripe; $1.15 \pm 0.09$, processed raw BPF; $0.57 \pm 0.08$, processed ripe BPF; $0.79 \pm 0.05$ and control; $0.09 \pm 0.04$, after $48 \mathrm{~h}$ of fermentation. Produced lactic acid and short chain fatty acids might be contributing increased percentage of titratable acidity.

\section{Antimicrobial activity against $E$. coli}

The inhibitory activity was distinct towards gram negative E. coli (Figure $4)$, common causative agent of large intestine. Highest zone of inhibition $(16.5 \pm 2.12 \mathrm{~mm})$ against $E$. coli was shown by supernatant obtained from incubation mixture of raw BPF compared to ripe $(11 \pm 2.82 \mathrm{~mm})$ and processed BPF.

\section{In vivo prebiotic investigation using Wistar male rats}

Four-week administration of raw BPF increased CFU/gm of Lactobacilli significantly in caecum content compared to ripe BPF (Table 3). Increased beneficial microbiota in caecum indicates improved beneficial micro flora of gut and vice versa. Table 3 showed significant increase in Lactobacilli spp. after administration of raw BPF $\left(8.57 \pm 0.07^{\mathrm{ab}} \log \mathrm{CFU} / \mathrm{g}\right)$ to male wistar rats compared to control $(8.04 \pm 0.03 \log \mathrm{CFU} / \mathrm{g})$. E. coli species of caecum content also decreased significantly when rats were fed with raw BPF $(5.03 \pm 0.15 \mathrm{Log}$ CFU/g of wet caecum content) to that of ripe BPF and control.

\section{DISCUSSION}

Disturbed microbial flora can be restored by probiotics, prebiotics and combination of two, referred as synbiotic. Probiotics were extensively studied and having safety records to its credit to restore disturbed gut microbiota. Sensitivity of probiotics to external environmental conditions such as temperature, $\mathrm{pH}$, humidity and internal environment like $\mathrm{pH}$ of GI tract renders it less effective for modulation of gut microbiota. ${ }^{15}$ Raw BPF significantly increased optical density, lowered the $\mathrm{pH}$ and showed less doubling time was observed for L. acidophilus to that of ripe, processed BPF and control. High dietary fibre content of raw banana makes it suitable for the growth of $L$. acidophilus. Reduced $\mathrm{pH}$ of the incubation mixture is an indirect measurement of acid produced during fermentation by L. acidophilus. As undigested BPF was subjected to in vitro fermentation; easily available substrate of BPF such as sucrose, fructose and glucose might be contributing to increase OD along with dietary fibre. All these substrate utilized by L. acidophilus to produce lactic acid and pyruvic acids using EmbdenMeyerhoff-Parnas pathway using NADH as the cofactor and the enzyme lactate dehydrogenase. Lactic acid and other fatty acids (short chain fatty acids) produced by Lactobacilli contributes to the maintenance of a low $\mathrm{pH}$ which is thought to be an important control mechanism preventing colonization by pathogens. Titratable acidity was also found to be increased by L. acidophilus, $L$. fermentum and L. casei when grown in presence of fructooligosaccharides as a prebiotic. ${ }^{16}$ Pyruvate is immediately converted to end products such as linear and branched SCFAs such as acetate, propionate, butyrate and carbon dioxide, hydrogen, methane, and water. These produced SCFAs also might be responsible for increase in percent titratable acidity. Lactic acid bacteria produce inhibitory compounds such as organic acids, hydrogen peroxide, diacetyl and bacteriocin. Bacteriocins are the ribosomally produced cationic proteins inhibit pathogenic bacteria living in the same ecological environment. Lactobacilli use bacteriocin as a 
Table 3: Effect of the intake of raw and ripe BPF ( $2 \mathrm{~g} / \mathrm{day} / \mathrm{rat})$, for 4 weeks, on the percentage of water, pH values, Lactobacilli and Bifidobacteria spp. in the caecum content of rats.

\begin{tabular}{cccccc}
\hline Treatment & $\begin{array}{c}\text { Lactobacilli spp. } \\
\text { (Log CFU/g of wet } \\
\text { caecum content) }\end{array}$ & $\begin{array}{c}\text { Bifidobacteria spp. } \\
\text { (Log CFU / g of wet } \\
\text { caecum content) }\end{array}$ & $\begin{array}{c}\text { E. coli } \\
\text { (Log CFU / g } \\
\text { of wet caecum } \\
\text { content) }\end{array}$ & $\begin{array}{c}\text { pH } \\
\text { Caecum\# }\end{array}$ & $\begin{array}{c}\% \text { water } \\
\text { Caecum\# }\end{array}$ \\
\hline Control & $8.04 \pm 0.03$ & $7.14 \pm 0.08$ & $5.83 \pm 0.20$ & $6.37 \pm 0.13$ & $72.4 \pm 1.5$ \\
Raw BPF & $8.57 \pm 0.07^{\mathrm{ab}}$ & $7.44 \pm 0.05$ & $5.03 \pm 0.15$ & $6.19 \pm 0.16$ & $76.7 \pm 1.2$ \\
Ripe BPF & $8.17 \pm 0.07$ & $7.30 \pm 0.05$ & $5.79 \pm 0.15$ & $6.41 \pm 1.0$ & $73.8 \pm 1.0$ \\
\hline
\end{tabular}

*Values presented as means and standard errors

Mean values with different superscripts are significantly different according to the Bonferroni's test $\left({ }^{\mathrm{a}} P<0.01\right.$ vs. Control group, ${ }^{\mathrm{b}} P<0.05$ vs. Ripe BPF).

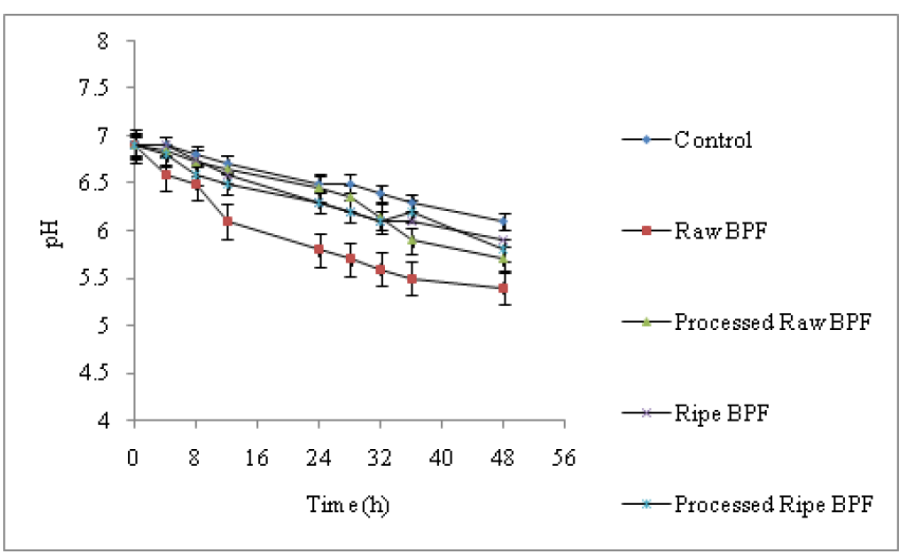

Figure 3: Changes in $\mathrm{pH}$ of reconstituted medium by L. acidophilus, in presence of raw, ripe and processed BPF.

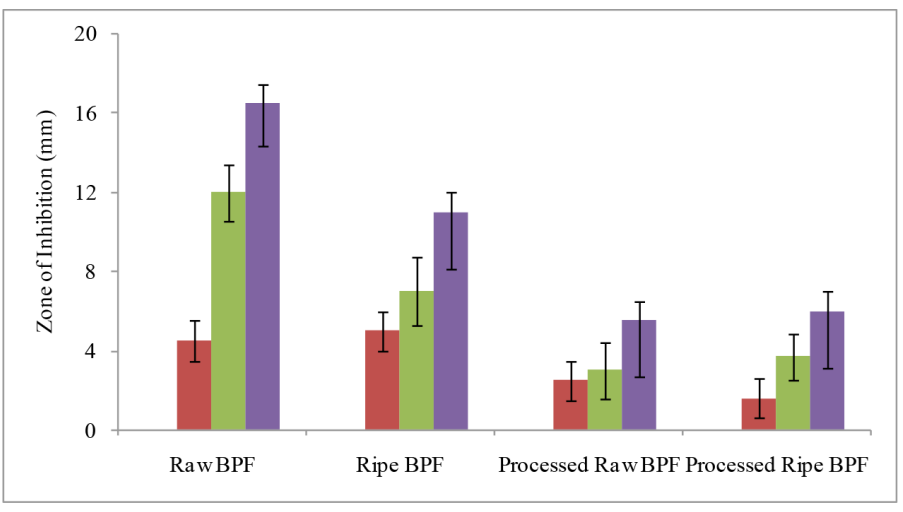

Figure 4: Antimicrobial activity of L. acidophilus containing raw, ripe and processed banana pulp against $E$. coli.

weapon for survival and use it against pathogenic bacteria. Bacteriocin has broad spectrum antimicrobial activity ${ }^{17}$ concluded that the bacteriocin is not effective against its own group member ${ }^{18}$ studied and confirmed the antimicrobial activity of bacteriocin produced by $L$. fermentum and $L$. acidophilus against cephalosporin resistant E. coli.

Bello-Perez et al. (1999) ${ }^{19}$ stated that the starch portion of food which can escape digestion in the human small intestine and pass into the colon referred as resistant starch.

Raw banana pulp is one of few sources of resistant starch-2. Partially crystalline nature of starch reduced susceptibility to amylase and resist digestion in upper gastrointestinal tract. Undigested resistant starch in upper gastrointestinal tract gets fermented in large intestine to produce SCFAs. Linear SCFAs such as acetate, propionate and butyrate have various health benefits to human health ${ }^{20}$ the ability of raw banana starch to reach at the large intestine increased the CFU/g of Lactobacilli spp. in caecum content of male wistar rats compared to ripe. Significant decrease in E. coli, common pathogen of large intestine was also observed in caecum content (Table 3 ). Increase in lactobacilli competitively inhibits the growth of pathogen such as E. coli. No significant increase in Bifidobacteria was observed after administration of raw BPF. In addition, the $\mathrm{pH}$ of the intestinal caecum content was decreased in in treated group. Significant decrease in $\mathrm{pH}$ during in vitro fermentation of raw BPF (Figure 3 ) and increase in titratable acidity (Table 2) showed correlation with lowered caecum $\mathrm{pH}$.

No significant increase in count of Lactobacilli in ripe BPF group compared to raw BPF could be due to breakdown of starch, hemicellulose and pectin substances resulting in softness of the tissue. Synthesis of fruit characteristics like volatiles, pigments and organic acid requires energy which is produced from the breakdown of starch. The enhancement in the activity of enzymes of glycolytic and Kreb's cycle help the fruit to assimilate energy as ATP produced from the breakdown. ${ }^{21}$ Therefore ripe banana showed less optical density, reduced lowered $\mathrm{pH}$ during in vitro fermentation study and less stimulation of Lactobacilli and Bifidobacteria in vivo study.

Modern food manufacturing methods destroy most forms of RS and make it unavailable to large intestine. Frying of banana to prepare chips may decrease availability of RS in colon drastically, which in turn not significantly increased the Lactobacilli and Bifidobacteria spp in caecum content. (Isolated colonies of Lactobacilli, Bifidobacterium and E. coli on specific agar were confirmed by respective biochemical tests and $16 \mathrm{~S}$ rDNA performed at Genombio Technologies Pvt. Ltd., data not shown) Lactic acid bacteria exclude adhesion of pathogens and enhances secretion of simple or complex molecules which regulates gut health. ${ }^{22}$ The formation of harmful amines and carcinogenic substances are reduced by lactic acid bacteria (Lactobacilli and Bifidobacteria) in the colon. ${ }^{23}$

Ingestion of unripe banana pulp not only beneficial because of starch but natural antioxidants polyphenols could confer additional health benefits to human health. ${ }^{24}$

\section{CONCLUSION}

Raw BPF significantly promoted the growth of L. acidophilus in vitro, because of presence of resistant starch. Daily administration of raw $\mathrm{BPF}$ to male wistar rats modulated intestinal environment via stimulating the growth of beneficial species and inhibiting the growth of pathogens. Other important constituents of banana such as potassium, iron, and vitamin $B_{6}$, sugars like glucose, sucrose and fructose 
can exhibit more health benefits. Polyphenols compounds of unripe banana flour would add up health benefits as natural antioxidants. In vitro and in vivo studies showed promising prebiotic potential of raw BPF.

\section{CONFLICT OF INTEREST}

The authors declare no conflict of interest.

\section{REFERENCES}

1. Zhang P, Whistler RL, BeMiller JN, Hamaker BR. Banana starch: Production, physicochemical properties, and digestibility-a review. Carbohydrate Polymers. 2005;59(4):443-58

2. Rashmi SB, Jyothsna V. Rural entrepreneurship: Exploring the opportunities from waste products of bananas plant in Karnataka. International Journal of Research in Computer Application and Management. 2011;1:105-7.

3. Langkilde AM, Champ M, Andersson H. Effects of high-resistant-starch banana flour (RS2) on in vitro fermentation and the small-bowel excretion of energy, nutrients, and sterols: An ileostomy study. The American Journal of Clinical Nutrition. 2002;75(1):104-11.

4. Topping DL, Clifton PM. Short-chain fatty acids and human colonic function: roles of resistant starch and non-starch polysaccharides. Physiological Reviews. 2001;81(3):1031-64.

5. WeaVer $\mathrm{C}$, Charley, H. Enzymatic Browning of Ripening BananasJournal of Food Science. 1974;39(6):1200-2.

6. Marriott J, Palmer JK. Bananas-physiology and biochemistry of storage and ripening for optimum quality. Food Science and Nutrition 1980;13(1):41-88.

7. Blankenship SM, Ellsworth $D D$, and Powell RL. A ripening index for banana fruit based on starch content. Hort Technology. 1993;3(3):338-9.

8. Saiullah R, Abbas FMA, Yeoh SY, Azhar ME. Utilization of green banana flour as a fuctional ingredient in yellow noodle. International Food Research Journal. 2009;16(3):373-9.

9. Mandalari G, Palop CN, Tuohy K, Gibson GR, Bennett RN, Waldron KW, et al. In vitro evaluation of the prebiotic activity of a pectin oligosaccharide rich extract enzymaticallly derived from bergamot peel. Applied Microbiology and Biotechnology 2007;73(5):1173-9.

10. Kask S, Adamberg K, Orłowski A, Vogensen FK, Moller PL, Ardo Y, et al. Physiological properties of L. paracasei, L. danicus and L. curvatus strains isolated from Estonian semi-hard cheese. Food Research International. 2003;36/910):1037-46
11. Chatterjee M, Manuel GAS, Hassan SS. Effect of Fruit Pectin on Growth of Lactic Acid Bacteria. Journal of Probiotics and Health. 2016;4:147.

12. Wang S, Zhu H, Lu C, Kang Z, LuoY, Feng L, et al. Fermented milk supplemented with probiotics and prebiotics can effectively alter the intestinal microbiota and immunity of host animalsJournal of Dairy Science. 2012;95(9):4813-22.

13. De Albuquerque C, Comalada M, Camuesco D, Rodrıguez-Cabezas $M$, Luiz-Ferreira A, Nieto A, et al. Effect of kale and papaya supplementation in colitis induced by trinitrobenzenesulfonic acid in the rat. E-SPEN, the European e-journal of clinical nutrition and metabolism. 2010;5(3):e111-e6.

14. Vinderola CG, Reinheimer JA. Culture media foor the enumeration of Bifidobacterium bifidum and Lactobacillus acidophilus in presence of yoghurt bacteria International Dairy Journal. 1999;9(8):497-505.

15. Wadher KJ, Mahore JG, Umekar MJ. Probiotics: Living Medicines in Health Maintenance And Disease Prevention. International Journal of Pharma and Bio Sciences. 2010;1(3):1-8

16. Mahore JG, Rohit BB, Deshkar SS. Investigation of Oligosaccharides for Prebitoic Action on Vaginal Lactobacilli. Journal of Young Pharmacists. 2017;9(4):502-6.

17. Ogunbawo ST, Sanni AL, Onilude AA. Charactereisation of bacteriocin produced by Lactobacillus plantarum F1 and Lactobacillus brevis OG1. African Journal of Biotechnology. 2003;2(8):219-27.

18. Riaz S, Nawaz SK, Hasnain S. Bacteriocin produced by L. fermentum L. acidophilus against cephalosporin resistant E. Coli. Brazilian Journal of Microbiology. 2010;41(3):643-8.

19. Bello-Perez LA, Agama AE, Sanchez HL, Paredes LO. Isolation and Partial Characterization of Banana Starches. Journal of Agricultural and Food Chemistry. $1999 ; 47(3): 854-7$.

20. Englyst HN, Cummings JH. Digestion of the carbohydrates of banana (Musa paradisiaca sapientum) in the human small intestine. The American Journal of Clinical Nutrition. 1986;44(1):42-50.

21. Surendranathan KK, Nair PM. Carbohydrate metabolism in ripening banana and its alteration on gamma irradiation in relation to delay in ripening. Journal of the Indian Institute of Science. 1980;2(C):63-80.

22. Molan AL, Lila MA, John MJ, Shampa De AE. In vitro and in vivo evaluation of the prebiotic activity of water-soluble blueberry extracts. World Journal of Microbiology and Biotechnology. 2009;25(7):1243-9.

23. Burns AJ, Rowland IR. Anti-carcinogenicity of probiotics and prebiotics. Current Issues in Intestinal Microbiology. 2000;1(1):13-24.

24. Vergara-Valencia FN, Granados-Pereza E, Agama-Acevedo E, Tovar J, Ruales J, Bello-Perez LA. Fibre concentrate from mango fruit: Characterization, associated antioxidant capacity and application as a bakery product ingredient. Lebensmittel-Wissenschaft and Technologie. 2007;40(4):722-9.

Article History: Submission Date : 05-12-2017 ; Revised Date : 17-02-2018; Acceptance Date : 12-03-2018.

Cite this article: Mahore JG, Shirolkar SV. Investigation of Effect of Ripening and Processing on Prebiotic Potential of Banana. J Young Pharm. 2018;10(4):40913. 